\title{
The dynamic lighting technique in indoor architecture
}

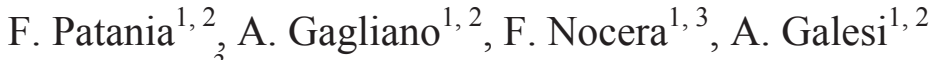 \\ \& J. Caserta $^{3}$ \\ ${ }^{1}$ Energy and Environment Division of D.I.I.M., Italy \\ ${ }^{2}$ Engineering Faculty of University of Catania, Italy \\ ${ }^{3}$ Architecture Faculty of University of Catania, Italy
}

\begin{abstract}
Light has a significant effect on the whole biological parameters of people. Its influences are found in many areas including the following:

- By means of human sight, light organizes the relationship between men and both living and lifeless of all creation in its entirety.

- The releasing into the human body of hormonal substances such as melatonin and cortisol are influenced by the light that, consequently, influences the well- being status of people such as body temperature, alertness and so on.

- The alternating of daytime and night time, that is the alternating of light and darkness, sets significantly the so called "biological clock" of man. According to that previously reported, light has a direct and significant impact on the behavior of people. So, while the emphasis in the past may have been primarily focused on the visual effects of lighting, the present efforts of research are focused on discovering the biological effects.

"Dynamic lighting" is an advanced technique that tries to bring the dynamic of daylight in indoor environments with the aim of creating a stimulating "natural" light that may enhances people's sense of well-being. According to this objective, the Authors have applied, using specialist software, the dynamic light technique to a model of minimalistic architecture used as offices, museums and exhibition halls. By the previous technique, people could control their own space according to their needs, mood and task, creating the right atmosphere by "dynamic light" to improve performance and motivation of their own job.
\end{abstract}


This paper wants to show the first step of results obtained in the case study by technical solutions suggested.

Keywords: dynamic light, well-being, comfort, minimalist architecture.

\section{Lighting and biological effects}

We normally think of the eye as an organ for vision, but due to the discovery of additional nerve connections from recently-detected novel photoreceptor cells in the eye to the brain, it is now understood how light also mediates and controls a large number of biochemical processes in the human body. The most important findings are related to the control of the biological clock and to the regulation of some important hormones through regular light-dark rhythms. This in turn means that lighting has a large influence on health, well-being and alertness. Light sends signals via the novel photoreceptor cells and a separate nerve system to our biological clock, which in turn regulates the circadian (daily) and circannual (seasonal) rhythms of a large variety of bodily processes. Figure 1 shows some typical rhythms in human beings. The figure shows only a few examples: body temperature, alertness, and the hormones cortisol and melatonin [1].

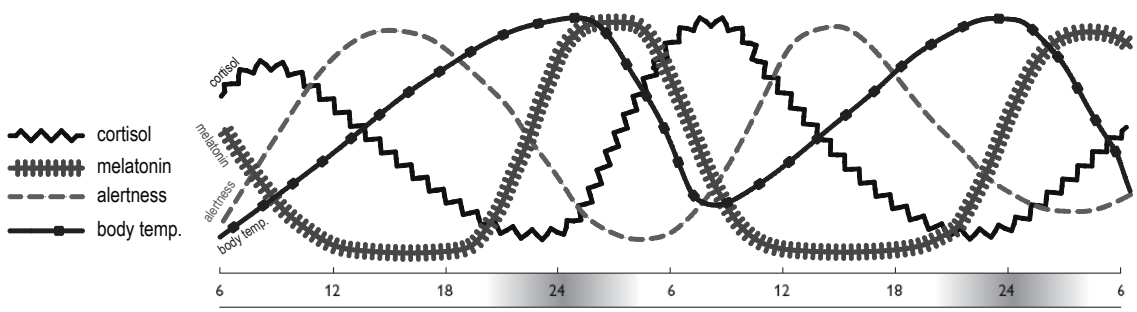

Figure 1: $\quad$ Some typical rhythms in human beings.

The hormones cortisol ("stress hormone") and melatonin ("sleep hormone") play an important role in governing alertness and sleep. It is the rhythm of day and night, of light and darkness that synchronises our biological clock. Accordingly, light has a direct and significant impact on people's alertness and well-being. So, while the emphasis in the past may have been primarily on the visual effects of lighting, now there is increasing interest in its biological effects too. It is possible, therefore, to use daily dynamics in lighting to improve performance, for example by varying illuminance and colour temperature according to the time of day. Higher illuminance levels with colder light will wake us up in the morning and make us more alert during the post-lunch dip. Low illuminances with a warm colour temperature have a calming effect. Two of the characteristics of light that strongly influence how we feel in a given environment are the brightness and colour appearance of the light. First of all, the light should always be bright enough to facilitate visual task performance, 
and better visual task performance results in better work performance. Increased lighting levels can also help to counter well-known effects such as the 'afterlunch dip' among day workers [2].

The colour appearance of the light also has substantial biological relevance. For example, the bluish light of morning has a stimulating effect on us, while the red sky of the early evening is relaxing. Daylight - the form of light with which we are most comfortable - is never constant. It changes throughout the day, affecting our emotions, moods, perception and performance [3, 4].

\section{The Kunsthalle}

The authors have designed a dynamic lighting system for a "Kunsthalle", an exhibition space dedicated to contemporary art, Figure 2. The Kunsthalle was designed to find a balanced relationship between art, architecture and nature. The idea was to create a hinge structure "hybrid" that confers a specific urban identity to the archaeological area of Syracuse, creating a zone filter to the archaeological site of Neapolis, carrying out a connection between the city and the archaeological zone. The project has drawn inspiration from minimalist architects such as Claudio Silvestrin and Tadao Ando.

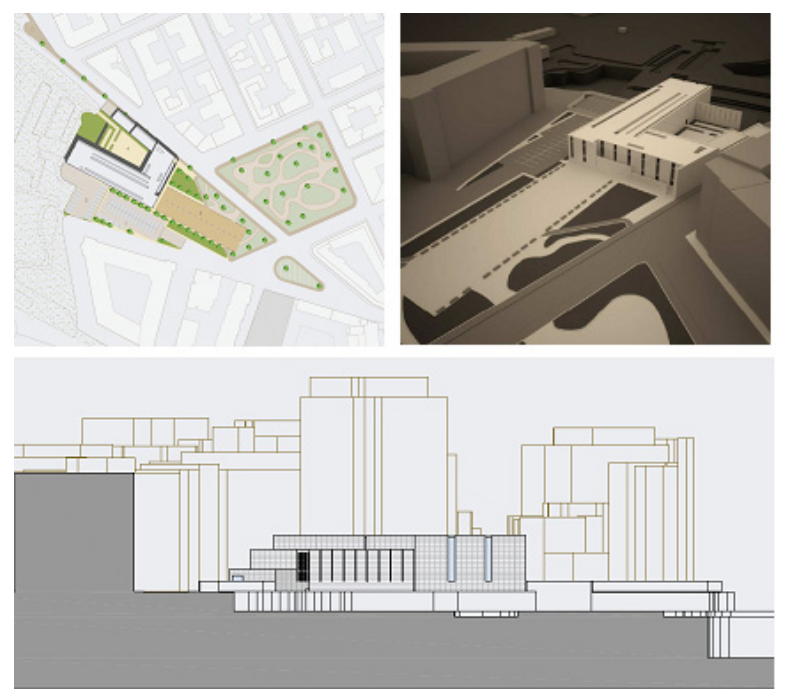

Figure 2: $\quad$ Some views of the Kunsthalle.

In the following sections, a detailed analysis will be performed of the comparison between a standard and dynamic lighting system for the office located in the Kunsthalle. The technical light design will be evaluated, the lighting parameters, the costs and benefits. Then, it will be exposed how the technical light design, applied to the environment taken as a reference, can be applied to the Exhibition Hall. 


\section{The standard and dynamic lighting system for an office}

As a first step, respecting the limits imposed by current regulations (EN 124641), the lighting design of the office located in the Kunsthalle was carried out using first the standard lighting system and then the dynamic lighting. The office is an open space and its dimensions are $17.5 \mathrm{mx} 5.6 \mathrm{mx} 3.7 \mathrm{~m}$ (Figure 3 ). The office has windows of size $0.2 \mathrm{mx} 1.70 \mathrm{~m}$ at a height of $2.0 \mathrm{~m}$ above the floor. The reflection coefficient of the walls are 0,5 . The reflection coefficient of the ceiling is 0,7 . The reflection coefficient of the floor is 0,2 . The desks and the other furniture have a reflection coefficient equal to 0,3 .

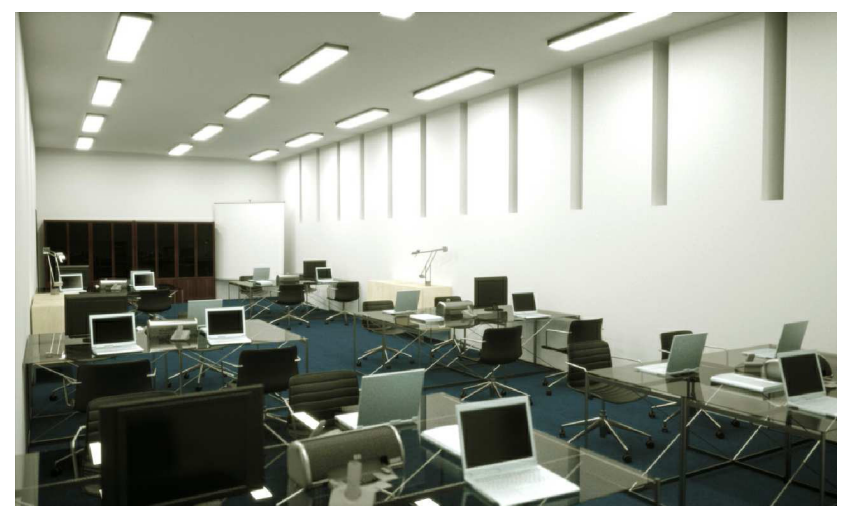

Figure 3: The office modeled with standard lighting.

The office lighting equipment has been arranged in three rows of six Philips type lighting fixtures, Savio model, version for mounting on the ceiling containing lamps 54W (TCS760-2xTL5-54W/840 Standard Lighting version and TCS770-3xTL5-54W/865/827/865 Dynamic Lighting version) with micro-lens optic (MLO) that allows Omni-directional Luminance Control (OLC), placed parallel to the facade. It has been calculated the horizontal illuminance level both for the standard scenario and the dynamic scenario using the human rhythm (Figure 5), not taking into account the day-lighting (Figures 6 and 7), using the software Relux.

Table 1 shows a summary of the results obtained using the software Relux for the two scenarios. The different values of total luminous flux of all lamps and, consequently, the different values of average illuminance are due to both the use of different types of lamps that the maintenance of the same uniformity of illumination for the two scenarios. It can be noted that the minimum value of average illuminance, required by EN 12464-1, is satisfied for both scenarios but in the dynamic scenario, with the same rate of luminous flux, the average illuminance is greater than $300 \mathrm{~lx}$ compared to the standard scenario. 


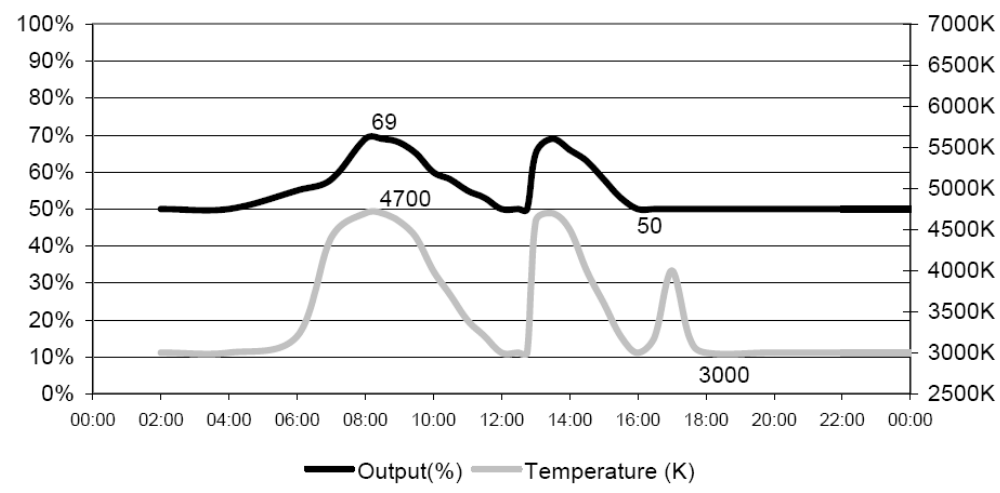

Figure 4: The graphs show the minimum and maximum values for both light output as color temperature.

Table 1: $\quad$ Comparison between standard and dynamic scenario (Relux data).

\begin{tabular}{|l|l|l|}
\hline & Standard Scenario & Dynamic Scenario \\
\hline Calculation algorithm used & \multicolumn{2}{|c|}{ high indirect fraction } \\
\hline Height of evaluation surface & \multicolumn{2}{|c|}{0,75} \\
\hline Height of luminaire plane & \multicolumn{2}{|c|}{3,70} \\
\hline Maintenance factor & \multicolumn{2}{|c|}{0,80} \\
\hline Total luminous flux of all lamps & $160200 \mathrm{~lm}$ & $233118 \mathrm{~lm}$ \\
\hline Total power & $2124 \mathrm{~W}$ & $3204 \mathrm{~W}$ \\
\hline Total power per area $\left(98.00 \mathrm{~m}^{2}\right)$ & $21,67 \mathrm{~W} / \mathrm{m}^{2}$ & $32,69 \mathrm{~W} / \mathrm{m}^{2}$ \\
\hline Average Illuminance $\left(E_{m}\right)$ & $5901 \mathrm{x}$ & $9101 \mathrm{x}$ \\
\hline Minimum Illuminance $\left(E_{\min }\right)$ & $91 \mathrm{x}$ & $1401 \mathrm{x}$ \\
\hline Maximum Illuminance $\left(E_{\max }\right)$ & $742 \mathrm{~lx}$ & $11401 \mathrm{x}$ \\
\hline Uniformity $\left(E_{\min } / E_{m}\right)$ & 0,15 & 0,15 \\
\hline Uniformity $\left(E_{\min } / E_{\max }\right)$ & 0,12 & 0,12 \\
\hline
\end{tabular}

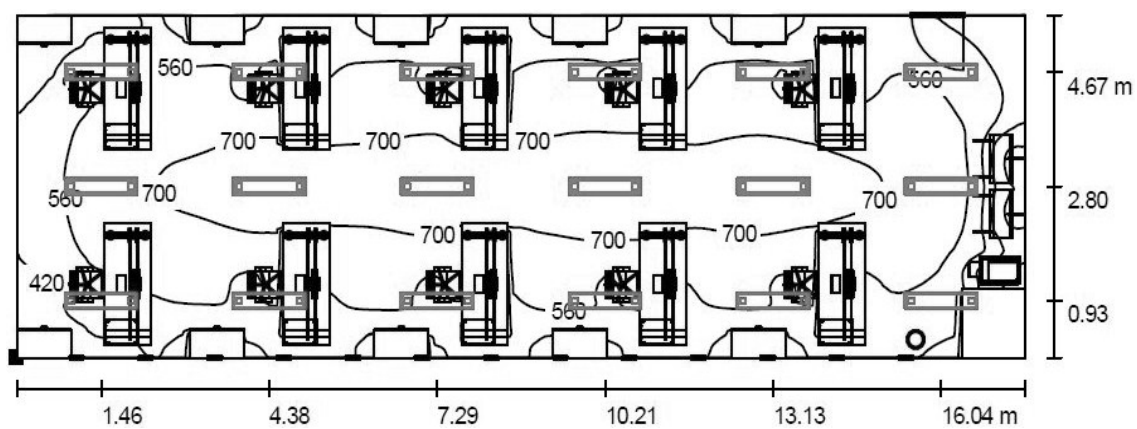

Figure 5: Horizontal illuminance levels for the standard scenario. 


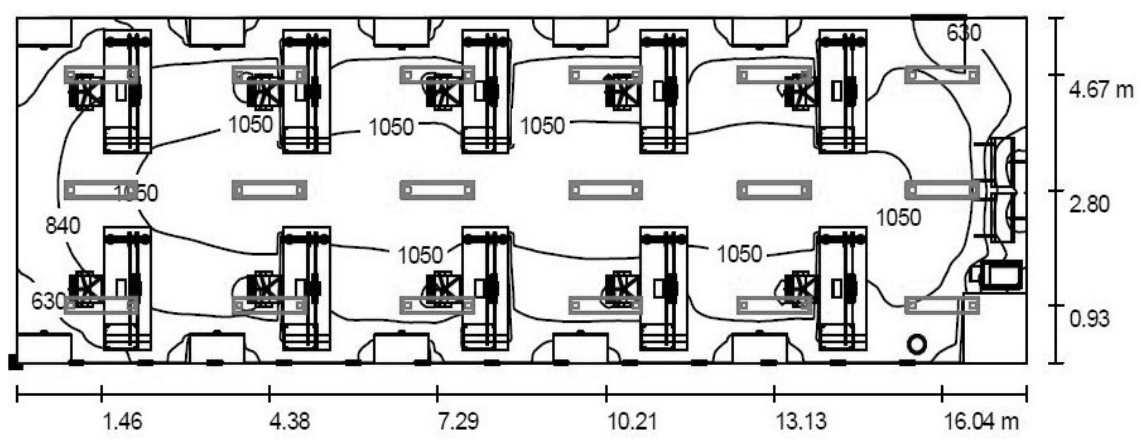

Figure 6: Horizontal illuminance levels for the dynamic scenario.

Tables 2 and 3 show that the values of the luminous flux and the color temperature remain constant over time for the standard scenario, while those values change over time for the dynamic scenario. Moreover, in the two tables the cost of electricity is set out over a year for both scenarios. The cost of electricity for the dynamic scenario is $12 \%$ greater than the standard.

The cost of the two lighting systems is the same while the cost of the lighting fixtures for the standard system and the dynamic system is different, which also requires a control unit and a set of modulation device. Consequently, the cost of a dynamic lighting system is greater than $44 \%$ compared with the standard

Table 2: $\quad$ Illuminance levels, luminous flux, color temperature and cost for the standard scenario.

\begin{tabular}{c|c|c|c|c|c|c|c}
\hline \multicolumn{7}{c}{ Standard Lighting } \\
\hline $\mathrm{h}$ & $E_{m}[\mathrm{~lx}]$ & Flux & Tcp $[\mathrm{K}]$ & $\begin{array}{c}\mathrm{P} \\
{[\mathrm{kW}]}\end{array}$ & $\mathrm{h} /$ year & $€ / \mathrm{kWh}$ & $€ /$ year \\
\hline $8: 00 / 18: 00$ & 590 & $100 \%$ & 4000 & 2,124 & 2400 & 0,13 & 662,69 \\
\hline
\end{tabular}

Table 3: Illuminance levels, luminous flux, color temperature and for the dynamic scenario.

\begin{tabular}{|c|c|c|c|c|c|c|c|}
\hline \multicolumn{8}{|c|}{ Dynamic Lighting } \\
\hline $\mathrm{h}$ & $E_{m}[\mathrm{~lx}]$ & Flux & $\operatorname{Tcp}[\mathrm{K}]$ & $\mathrm{P}[\mathrm{kW}]$ & $\mathrm{h} /$ year & $€ / \mathrm{kWh}$ & $€ /$ year \\
\hline 8:00 & 709 & $78 \%$ & 4400 & 2,499 & 240 & 0,13 & 77,972 \\
\hline 9:00 & 709 & $78 \%$ & 4400 & 2,784 & 240 & 0,13 & 86,860 \\
\hline $10: 00$ & 873 & $96 \%$ & 3800 & 2,816 & 240 & 0,13 & 87,859 \\
\hline $11: 00$ & 728 & $80 \%$ & 3500 & 3,304 & 240 & 0,13 & 71,884 \\
\hline 12:00 & 582 & $64 \%$ & 3000 & 2,080 & 240 & 0,13 & 64,896 \\
\hline $13: 00$ & 591 & $65 \%$ & 4900 & 2,080 & 240 & 0,13 & 64,896 \\
\hline $14: 00$ & 591 & $65 \%$ & 4900 & 3,304 & 240 & 0,13 & 71,884 \\
\hline 15:00 & 728 & $80 \%$ & 4250 & 2,400 & 240 & 0,13 & 74,880 \\
\hline 16:00 & 637 & $70 \%$ & 4500 & 2,560 & 240 & 0,13 & 79,872 \\
\hline 17:00 & 819 & $90 \%$ & 4000 & 2,560 & 240 & 0,13 & 79,872 \\
\hline 18:00 & 728 & $80 \%$ & 4250 & 2,499 & 240 & 0,13 & 77,972 \\
\hline & & & & & & Total & 760,87 \\
\hline
\end{tabular}


lighting system. Table 4 shows the cost of the lighting fixtures for the two systems. The cost comparison has been made for 32 luminaire because it is the maximum number of luminaire that the controller can handle and it is convenient to handle the maximum possible number of luminaire.

Table 4: The cost comparison of the lighting fixtures.

\begin{tabular}{|c|c|c|c|}
\cline { 2 - 4 } \multicolumn{1}{c|}{} & Cost (€) & N & Total (€) \\
\hline Standard Lighting & & & \\
\hline Luminaire TCS760 & 530 & 32 & 16960 \\
\hline & & & \\
\hline Dynamic Lighting & & & \\
\hline Luminaire TCS770 & 800 & 32 & 25600 \\
\hline Kit Dynamic Lighting & 4000 & 1 & 4000 \\
\hline Control unit & 700 & 1 & 700 \\
\hline
\end{tabular}

Although the cost of a dynamic system is greater than the standard, it has to be remembered that some of the economic losses of a company are caused by the absence of the employees and this is often due to non-healthy lighting. We considered that this part of economic loss attributed to the absence could have been to transform into an economic gain for the company by using a system of dynamic lighting. In fact, the research shows that one of the positive effects induced by the increase on well-being produced by a dynamic lighting is the decrease of the absenteeism that can be quantified from $8 \%$ to $12 \%$ [1]. The reduction in absenteeism could lead the company to an economic gain and it could help to offset costs of investments over time. Figure 8 shows the cost of construction and management (annual energy cost and maintenance) for the dynamic system and standards.

The graph also shows the economic trend of the investment due to lower percentages of non-absenteeism $(8 \%, 10 \%, 12 \%)$ thanks to the dynamic lighting system.

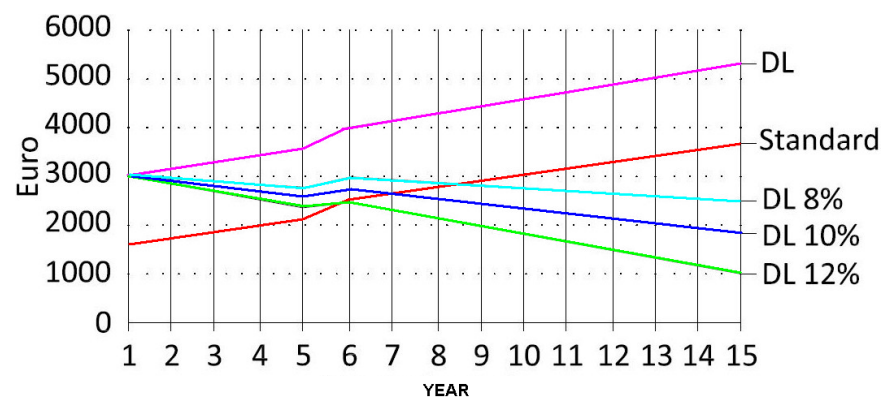

Figure 7: The cost of construction and management.

For the above chart the following program of maintenance was taken into account:

- maintenance lamps: $3^{\text {rd }}, 5^{\text {th }}, 9^{\text {th }}, 11^{\text {th }}, 13^{\text {th }}$ year;

- maintenance and replacement lamps: $7^{\text {th }}$ year. 


\section{The Exhibition Hall}

As in the previous section, a modellation of the Exhibition Hall has been performed and applied both the standard lighting system and the dynamic lighting system. In this case, however, we focused on software capable of modeling the dynamic light. To this aim, several simulations with Fryrender software have been performed. Fryrender is a photo-realistic render engine where all the elements involved in the generation of the final image (materials, lights and cameras) are based on physically accurate models. It is not a classical render engine, but a physics simulator that reproduces the governing Laws of light radiation and optics accurately. This light simulation is performed using unbiased integration techniques that ensure that the render will converge to the exact real light balance, provided enough time for the computations.

In the dynamic lighting simulation, the Exhibition Hall equipment has been arranged in two rows of twenty-eight Philips type lighting fixtures, Savio model, version for mounting on the ceiling containing lamps 35W (TCS770-3xTL5$54 \mathrm{~W} / 865 / 827 / 865)$. In the standard lighting simulation, the Exhibition Hall equipment has been arranged in four rows of fourteen Zumtobel type lighting fixtures, SLOT model, version for mounting on the ceiling containing lamps 54W (Slot 3x1 54W PMMA LDE IP54). The horizontal and vertical illuminance level both for the standard scenario and the dynamic scenario using the human rhythm has been calculated, not taking into account the day-lighting using the software Relux and then modeling the environment using the software Fryrender.
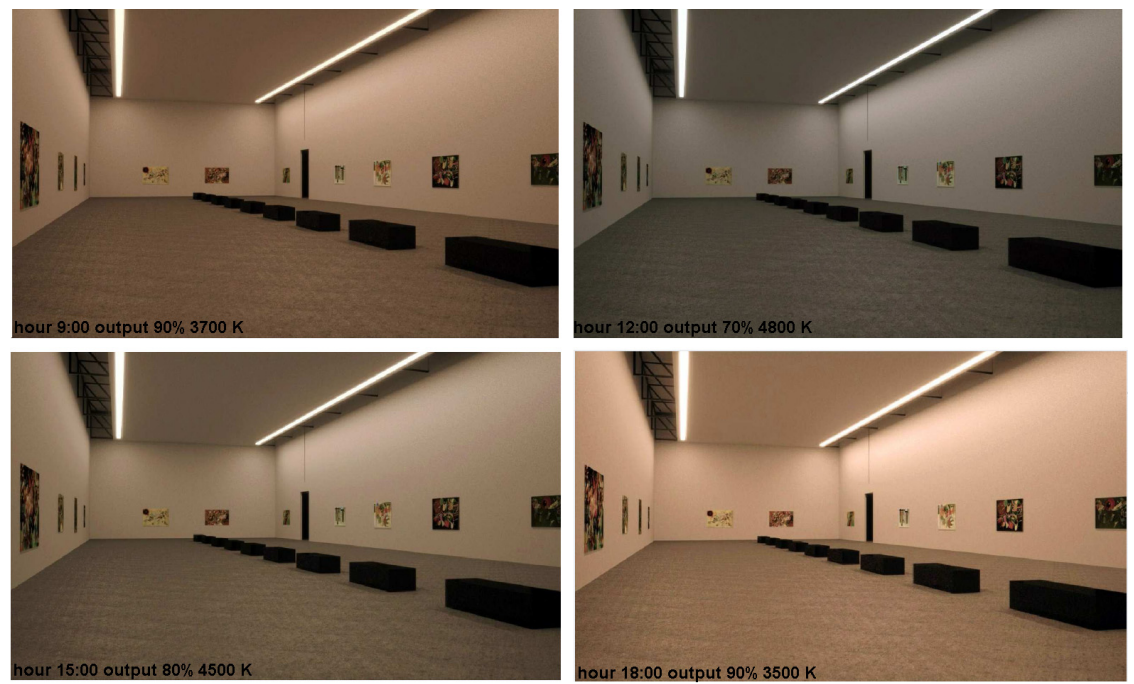

Figure 8: The images of the Exhibition Hall with dynamic lighting system at different hours of the day. 
Table 6 shows the comparison of the summary of results obtained in the two scenarios. Figure 9 shows four frames of the simulation of dynamic lighting with natural biorhythm. Figure 10 shows the image of the simulation of standard lighting. Figure 5 shows the comparison of the variation of dynamic lighting with the standard lighting.

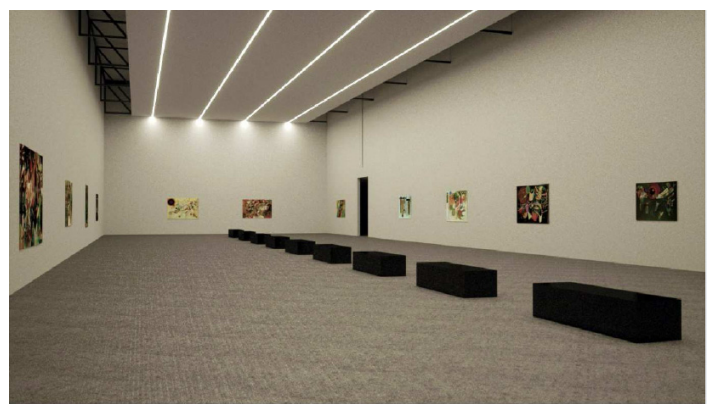

Figure 9: The images of exhibition Hall with standard lighting system.

Table 5: $\quad$ Comparison between standard and dynamic scenario (Relux data).

\begin{tabular}{|l|l|l|}
\hline & Standard Scenario & \multicolumn{1}{|c|}{ Dynamic Scenario } \\
\hline Calculation algorithm used & \multicolumn{2}{|c|}{ high indirect fraction } \\
\hline Height of evaluation surface & \multicolumn{2}{|c|}{7,75} \\
\hline Height of luminaire plane & \multicolumn{2}{|c|}{0,90} \\
\hline Maintenance factor & \multicolumn{2}{|c|}{0,80} \\
\hline Total luminous flux of all lamps & $747600 \mathrm{~lm}$ & $532056 \mathrm{~lm}$ \\
\hline Total power & $9945.6 \mathrm{~W}$ & $6496 \mathrm{~W}$ \\
\hline Total power per area $\left(695,72 \mathrm{~m}^{2}\right)$ & $14,30 \mathrm{~W} / \mathrm{m}^{2}$ & $9,34 \mathrm{~W} / \mathrm{m}^{2}$ \\
\hline Average Illuminance $\left(E_{m}\right)$ & $311 \mathrm{~lx}$ & $311 \mathrm{~lx}$ \\
\hline Minimum Illuminance $\left(E_{\min }\right)$ & $122 \mathrm{x}$ & $111 \mathrm{~lx}$ \\
\hline Maximum Illuminance $\left(E_{\max }\right)$ & $397 \mathrm{~lx}$ & $413 \mathrm{~lx}$ \\
\hline Uniformity $\left(E_{\min } / E_{m}\right)$ & 0,39 & 0,36 \\
\hline Uniformity $\left(E_{\min } / E_{\max }\right)$ & 0,31 & 0,27 \\
\hline
\end{tabular}

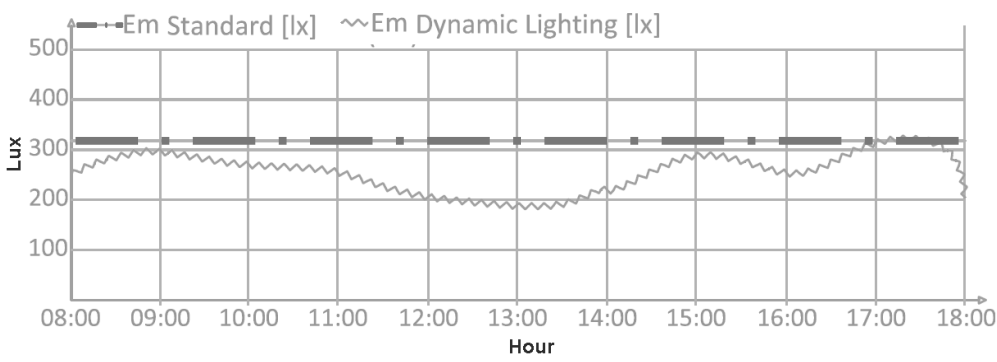

Figure 10: Comparison of illuminance between the dynamic lighting trend and standard lighting. 


\section{Conclusions}

The analysis of the results can lead to the following final considerations:

- The application of a dynamic lighting system surely offers some benefits to an environment: well-being, comfort, relaxation. The benefits are especially evident in environments like offices and they can be assessed economically only as a decrease of absenteeism in the workplace

- The dynamic lighting system can lead to minimum but not significant energy savings compared to standard lighting system.

- As things stand now, the cost of the equipment of a dynamic lighting system is not economical compared with the standard system, however:

- The dynamic lighting system opens new possibilities for artistic lighting of the exhibition spaces and gives them a feeling of open space.

The next step of research will be to verify the energy savings analyzing the dynamic lighting coupled with day-lighting

\section{References}

[1] Henri Juslén, Improving healthcare with light, Philips Lighting

[2] Brill T.B., Lights interaction with art and antiquities, Plenum Press, New York, 1980

[3] Frye M., Light in museums and galleries, Concord Lighting Ltd, London, 1985

[4] Banks P.M., Moore L.A., Liu C., Wu B., Dynamic visual acuity: a review. S.Afr. Optometry, 63(2), 58-64. 2004. 